\title{
STRUCTURAL PERFORMANCES OF RC BEAMS STRENGTHENED WITH STEEL REINFORCED GEOPOLYMERIC MATRIX (SRGM)
}

\section{FRANCESCO BENCARDINO AND ANTONIO CONDELLO*}

\author{
University of Calabria, Cosenza, Italy \\ e-mail: francesco.bencardino@unical.it \\ e-mail: antonio.condello@unical.it
}

\begin{abstract}
Key words: Debonding, Fracture, Reinforced Concrete, Repair, Steel Reinforced Geopolymeric Matrix, Strengthening.
\end{abstract}

\begin{abstract}
The work aims to investigate the structural performances of an innovative solution, alternative to Externally Bonded (EB) technique, for retrofitting of Reinforced Concrete (RC) structures with deteriorated cover concrete and/or corroded bars: Inhibiting-RepairingStrengthening (IRS). It consists in the installation of a stainless steel fabric in the cover concrete, restoring the latter with a geopolymeric matrix (Steel Reinforced Geopolymeric Matrix, SRGM). The IRS solution is an eco-friendly technology that also reduces the time and the costs of the intervention. In order to simulate existing RC structures, two groups of large-scale RC beams were casted with low concrete strength and corroded smooth round/ribbed bars. Four RC beams were strengthened with IRS-SRGM and EB-SRGM systems and monotonically tested under four-points bending. Test results show that the IRS-SRGM system provides greater load carrying capacity and ductility than the EB-SRGM system. Finally, a theoretical prediction of the tested beams, by means of a fracture mechanics based model, is carried out. The analytical/experimental comparisons are satisfactory.
\end{abstract}

\section{INTRODUCTION}

The most of the existing Reinforced Concrete (RC) structures and infrastructures that need retrofitting have deteriorated cover concrete and/or corroded internal steel bars. Traditionally, these RC members have been repaired with steel plates and/or Fiber Reinforced Polymer (FRP) composite materials [1-4]. With reference to the Externally Bonded (EB)-FRP system, the following independent operations are requested $[5,6]$ : removal of the deteriorated concrete, application of a corrosion inhibitor on internal reinforcing bars, repairing/restoring of the cover concrete and then installation of the strengthening system. These operations, due to the used materials, pollute environment.

Currently, besides the FRP a new class of composite materials, based on inorganic matrices, is developing. Different cement based strengthening systems for RC structures were proposed: Textile Reinforced Concrete (TRC), Textile Reinforced Mortar (TRM), Fiber Reinforced Cementitious Matrix
(FRCM), Fiber Reinforced Grout (FRG) [716]. Among these, considering the high rate of environmental pollution, for going towards the use of environmentally friendly materials, fireproof geopolymeric matrices are emerging in the civil engineering field [17, 18]. These inorganic matrices have significant advantages compared to the traditional epoxy resin used for FRP system, such as: excellent resistance to corrosion, high value of transition temperature (about $800^{\circ} \mathrm{C}$ ), no emission of toxic gases under intense fire, excellent durability even in strong aggressive conditions (coastal areas, deicing salts, acid rain), high resistance against sulfates [17-19]. A further advantage of the geopolymeric matrices compared to epoxy adhesives is related to their inorganic silico-aluminate nature, which makes these materials similar and alternative to cementitious materials, due to high mechanical properties and environmental advantages. In fact, geopolymers generates $80 \%$ less carbon dioxide and the global warming potential is $70 \%$ lower than Ordinary Portland Cement (OPC ) [18]. Furthermore, 
future increase cost on carbon dioxide emissions generated during clinker production, will increase the economic and environmental advantage of the geopolymer based materials. The idea of using this type of matrix for structural applications has been already investigated [12, 17, 18].

In the present work, a new potential structural application of the geopolymers was experimentally evaluated. Specifically, the geopolymeric matrix was used, at the same time, as corrosion inhibitor, repairing/restoring layer and binding agent to embedded a stainless steel strengthening fabric in the cover concrete. The proposed solution, alternative to EB technique, was conceived for upgrading of $\mathrm{RC}$ structures with deteriorated cover concrete and/or corroded bars. It includes three operations in one, Inhibiting-RepairingStrengthening (IRS), and consists in the installation of a new eco-friendly composite system (Steel Reinforced Geopolymeric Matrix, SRGM) during the repairing/restoring of the cover concrete (IRS-SRGM).

Although the economic and environmental advantages are relevant, it is necessary assess the structural effectiveness of the IRS solution, comparing it with traditional EB technique. To this purpose, an experimental investigation was carried out on two groups of three largescale RC beams, each one, strengthened with EB-SRGM and IRS-SRGM systems. A theoretical analysis, through a fracture mechanics based approach proposed for the FRP system [20], was also performed. The experimental results highlighted the good structural performance of the new IRS technique. Experimental and analytical comparisons showed the reliability and adaptability of the fracture based model to predict the behavior of the tested beams.

\section{EXPERIMENTAL PROGRAM}

\subsection{Geometrical and mechanical properties}

Two groups of beams (A and B) were designed and tested. Each group includes three RC beams: one beam strengthened with IRSSRGM system (A-IRS, B-IRS), one beam externally strengthened with EB-SRGM system (A-EB, B-EB) and another unstrengthened control beam (A-CB, B-CB). Geometrical parameters and strengthening configurations of the tested beams are shown in Figure 1 and the values are given in Table 1.

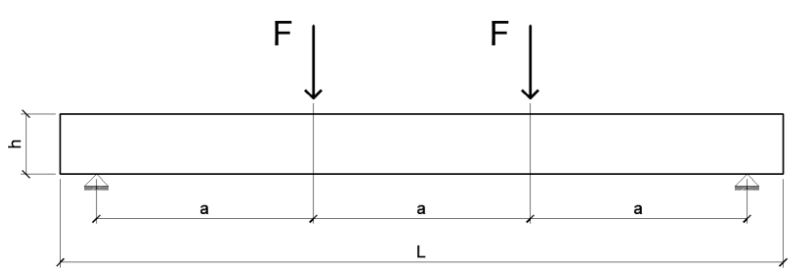

(a) RC unstrengthened beam

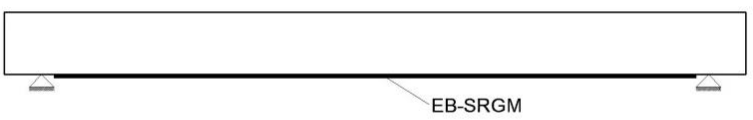

(b) RC beam strengthened with EB-SRGM system

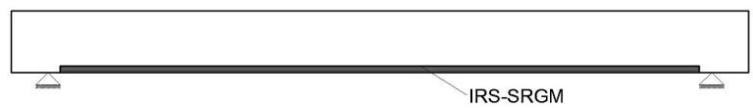

(c) RC beam strengthened with IRS-SRGM system

Figure 1: Geometry of the tested beams.

For each group are summarized: length $(L)$, width $(b)$, and height $(h)$ of the beams; shear or bending span $(a)$; length to height ratio $(L / h)$; shear or bending span to depth ratio $(a / d)$; area of the tension $\left(A_{s}\right)$ and compression $\left(A_{s}^{\prime}\right)$ longitudinal steel reinforcements; reinforcement ratio of $A_{s}$ over the cross sectional area $\left(\rho_{s}\right)$. It should be noted that the geometrical parameters $b, L / h, a / d, \rho_{s}$ are equal for both groups. Also the width of the strengthening system $\left(b_{f}\right)$ was defined by keeping constant the strengthening ratio $\left(\rho_{f}\right)$ of reinforcing area $\left(A_{f}\right)$ over the cross sectional area. As a result, the beams were strengthened with a single ply of steel fabric and $b_{f}$ was equal to $100 \mathrm{~mm}$ and $150 \mathrm{~mm}$ for the beams of the groups $\mathrm{A}$ and $\mathrm{B}$, respectively $\left(\rho_{f}=0.06 \%\right)$. This geometrical configuration of the beams allows evaluate, comparing the test results of both groups, a possible scale effect as well as the structural effectiveness of the traditional (EB) and proposed (IRS) techniques. 
Table 1: Geometrical parameters of the tested beams

\begin{tabular}{ccccccccccc}
\hline Group & $L$ & $b$ & $h$ & $L / h$ & $a$ & $a / d$ & $A_{s}$ & $\rho_{s}[\%]$ & $A_{s}^{\prime}$ & Stirrups \\
\hline A & 3000 & \multirow{2}{*}{150} & 250 & \multirow{2}{*}{12} & 900 & \multirow{2}{*}{4.1} & $2 \Phi 12$ & \multirow{2}{*}{0.6} & $2 \Phi 8$ & \multirow{2}{*}{$\Phi 8 / 150 \mathrm{~mm}$} \\
B & 4800 & & 400 & & 1500 & & $2 \Phi 16$ & & \\
\hline
\end{tabular}

The mechanical properties of the concrete and internal steel reinforcement were experimentally evaluated. Specifically, the average concrete compressive $\left(f_{c m}\right)$ and tensile (slip test, $f_{c t m}$ ) strengths, at 28 days, on twelve (six for each test) cylindrical samples $(150 \mathrm{~mm}$ x $300 \mathrm{~mm}$ ) were $16.8 \mathrm{MPa}$ and $1.7 \mathrm{MPa}$, respectively. The average yielding strengths $\left(f_{y m}\right)$ of the internal steel bars, on three samples for each diameter, were $543.8 \mathrm{MPa}, 367.1$ $\mathrm{MPa}$ and $492.0 \mathrm{MPa}$ for the $8 \mathrm{~mm}, 12 \mathrm{~mm}$ (smooth round bars) and $16 \mathrm{~mm}$ diameters, respectively.

\subsection{SRGM system}

The composite material consists of a new stainless steel fabric/strip embedded in an inorganic geopolymeric fireproof matrix. It was applied on RC beams with traditional (EB) or innovative (IRS) technique.

The steel strip is an unidirectional reinforcing fabric made of stainless Ultra High Tensile Strength Steel (UHTSS) cords, particularly resistant to corrosion, suitable for interventions on substrates subject to rising damp and/or exposed to aggressive environments [21]. The geopolymeric matrix is an inorganic material with the addition of synthetic fibers, suitable for structural repairs (cover concrete) being able to be applied with thicknesses between $2 \mathrm{~mm}$ and $40 \mathrm{~mm}$. It offers resistance to corrosion and excellent durability even in strong aggressive conditions [22].

Due to the properties of the two constituent materials, the SRGM system can be applied on corroded bars, concrete substrates deteriorated and/or exposed to aggressive environments. Furthermore, SRGM system is a green technology.

\subsection{Surface preparation}

With reference to the EB technique, before bonding of the external reinforcing system to the beams, the bottom surface of each beam was carefully cleaned in order to remove dust, loose parts, oil stains, and other parts that could affect the bonding. Subsequently, the concrete surface was subjected to moist sandblasting and hydraulic scouring (Figure 2(a)).

With reference to the IRS technique, the specimens were casted in the mould without the cover concrete. Subsequently, the concrete around to the bottom longitudinal reinforcing bars was removed to inhibit/protect the corroded bars through the application of the geopolymeric matrix (Figure 2(b)).

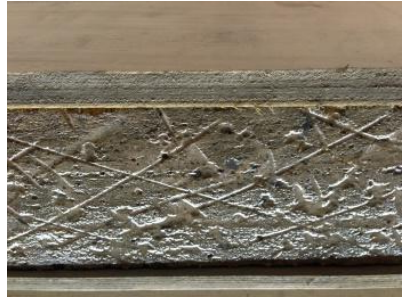

(a) Surface preparation (EB)

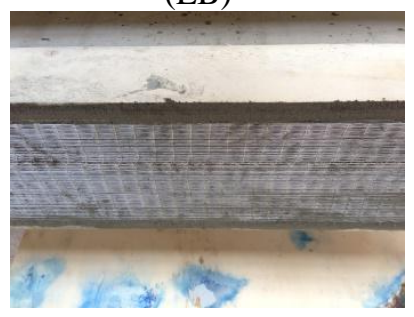

(c) Reinforcing fabric application (EB-SRGM)

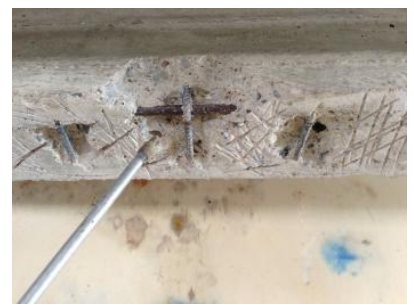

(b) Surface preparation (IRS)

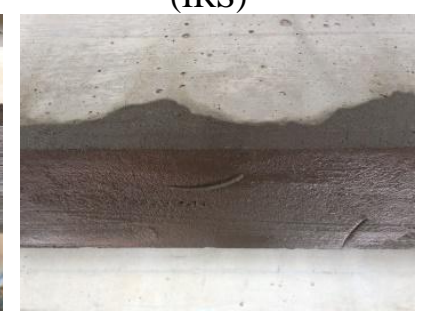

d) Installation completed (IRS-SRGM)
Figure 2: Surface preparation and bonding procedure.

Although the preparation of the concrete substrate for the two strengthening techniques was different, the same application procedure of the SRGM system was used. The concrete surface was wetted with water and then covered by a first layer of geopolymeric matrix using a smooth metal trowel. The steel fabric was placed on it and lightly pressed using a metal spreader to ensure the fabric sank completely into the matrix. A second layer of matrix was applied to completely cover the reinforcing fabric $(\mathrm{EB})$ and to restore 
the cover concrete (IRS). The surface preparation and the bonding procedure are shown in Figs. 2(a)-(d).

\subsection{Instrumentation}

The beams were internally and externally instrumented and tested under four-points bending. Two vertical loads were applied symmetrically to the midspan of the beams with a constant bending moment region and a constant shear span. All the beams of the two groups (A and B) were simply supported and tested with a shear span to depth ratio of $a / d=$ 4.1. The test set-up is shown in Figure 3.

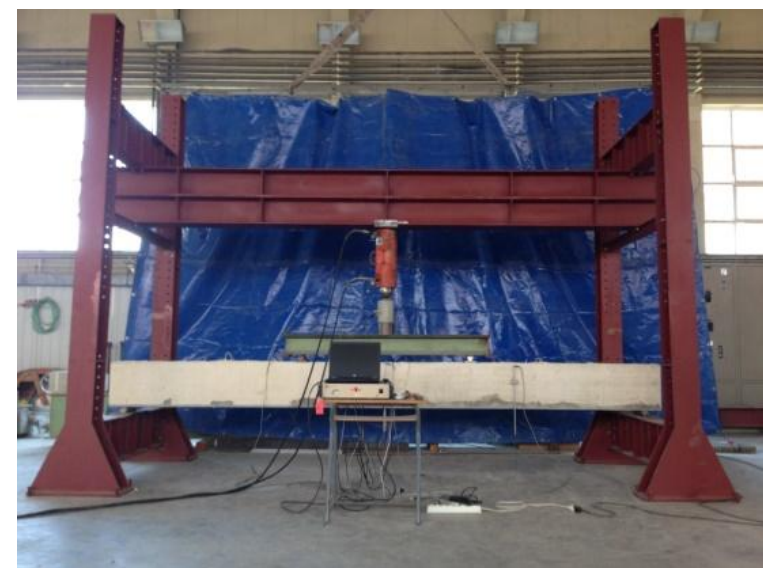

Figure 3: Test set-up.

Applied load, vertical displacements, and strains of all the materials were monitored during the tests. Displacements were measured at midspan and at a quarter of the span using Linear Variable Displacement Transducers (LVDTs). In order to measure the material strains in the midspan section, three strain gages were attached to the internal reinforcing bars (specifically, one on the top bars and two on the bottom bars) and two strain gages were placed on the compression zone of the top concrete surface. Also the strains on the strengthening systems were monitored and recorded using two strain gages for each strengthened beam.

The load was monotonically applied to the beams by means of a hydraulic actuator and recorded using a $300 \mathrm{kN}$ load cell. All the data obtained from load cell, strain gages, and LVDTs were recorded through a data acquisition system. During the tests, the load was periodically paused in order to identify and mark crack formations and growth.

\section{EXPERIMENTAL RESULTS}

\subsection{Structural behavior}

The load-midspan deflection curves are shown in Figure 4 and deflections of the beams under maximum load are shown in Figure 5. Specifically, Figures 4(a), 5(a) and Figures 4(b), 5(b) show the results for the beams of the groups A and B, respectively.

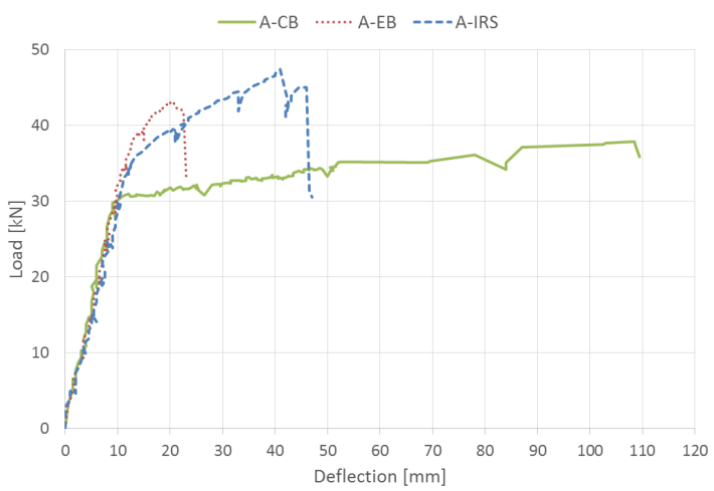

(a) Group A

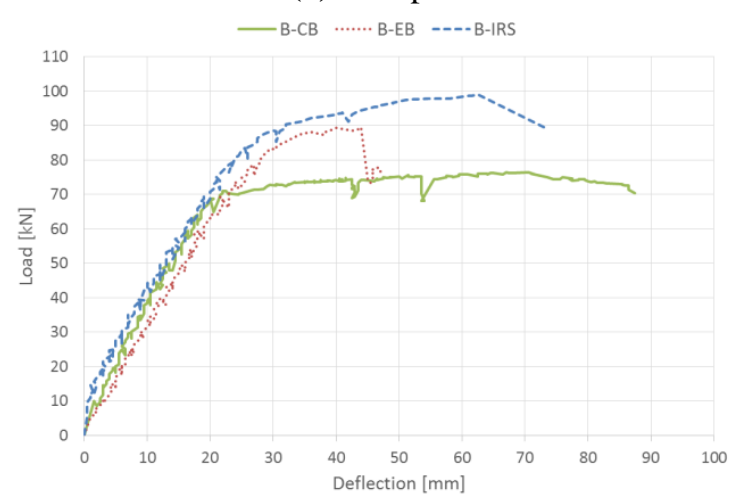

(b) Group B

Figure 4: Load-midspan deflection curves.

It should be noted that both the EB-SRGM and IRS-SRGM strengthening systems improved the load carrying capacity and decreased the ultimate deflections, and then the ultimate rotations, of the corresponding $\mathrm{RC}$ control beam. Furthermore, the structural behavior of the RC beams strengthened with the IRS technique (A-IRS, B-IRS) was better, in terms of ultimate load and deflections, compared to the corresponding $\mathrm{RC}$ beams strengthened with traditional EB technique (A$\mathrm{EB}, \mathrm{B}-\mathrm{EB})$. 
The strain profiles in the midspan section at failure, for both groups, are given in Figure 6 . It can be observed that the strain profiles of the strengthened beams were not perfectly linear at failure (and in proximity to it) due to the slippage at the UHTSS cords-matrix and/or SRGM-concrete interfaces. This phenomenon was more relevant on the beams of the group B than the group A.

The slope of the strain profiles represents the curvature of the cross-section (see Figure $6)$. The curvature of the beams strengthened with IRS-SRGM system (A-IRS, B-IRS) was greater than the corresponding beams strengthened with EB-SRGM system (A-EB, $\mathrm{B}-\mathrm{EB})$ and lower than the corresponding control beams (A-CB, B-CB). This highlights that the proposed IRS technique allows to regain a part of the curvature ductility lost due to the EB, and further increases the load carrying capacity of the strengthened member.

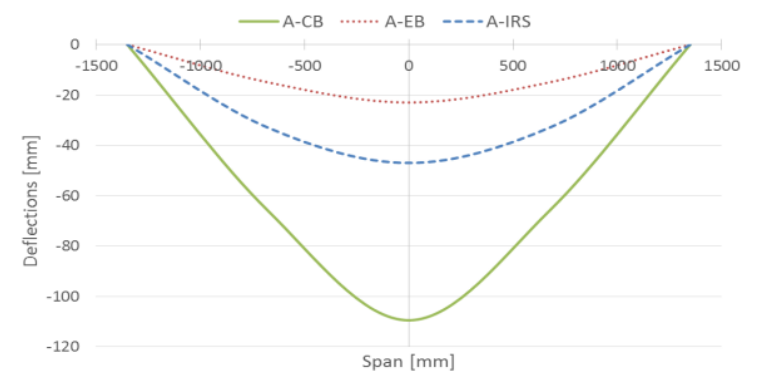

(a) Group A

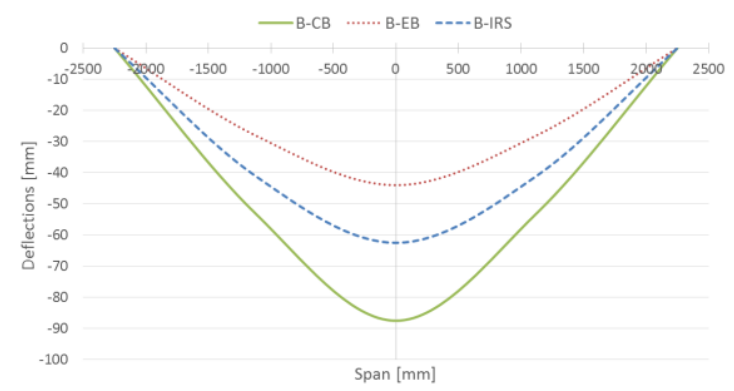

(b) Group B

Figure 5: Deflections under maximum load.

Test results, in terms of loads at critical stages and ultimate strains, are given in Table 2. Specifically, $F_{c r}, F_{y}$ and $F_{u}$ are the load values at first visible flexural crack, at yielding of the internal tension steel bars and at failure, respectively. The $\varepsilon_{c}, \varepsilon_{s}$ and $\varepsilon_{f}$ strains were measured in the midspan section at failure on the concrete top surface of the beams, on the bottom tension steel bars and on the UHTSS cords, respectively.

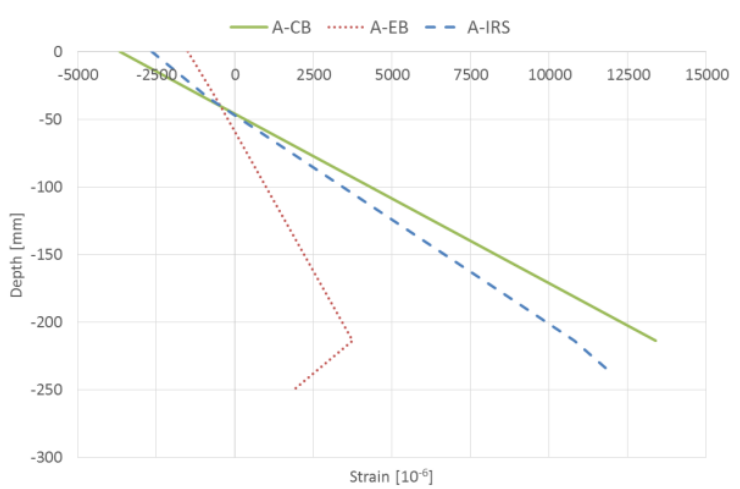

(a) Group A

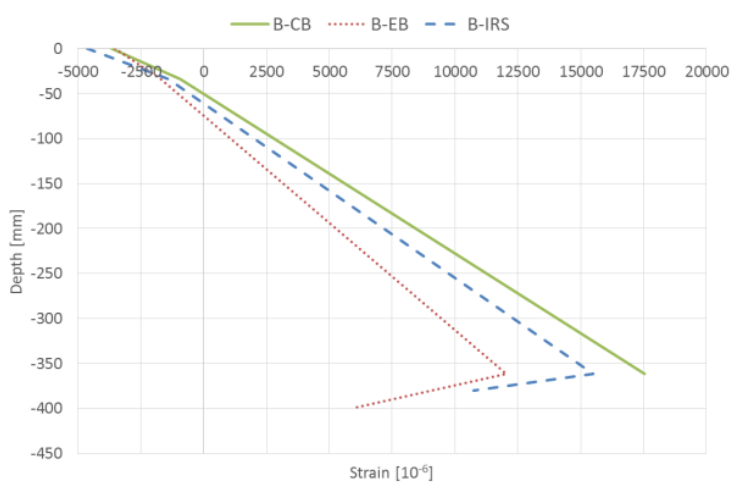

(b) Group B

Figure 6: Strain profiles at failure.

The UHTSS strain $\left(\varepsilon_{f}\right)$ for the beams A-IRS and B-IRS achieved about $11 \%$, whereas it reached $1.87 \%$ and $5.99 \%$ for the beams A$\mathrm{EB}$ and B-EB, respectively. This clearly highlights the effectiveness of the IRS-SRGM system. The failure modes, for all the strengthened beams are shown in Figure 7.

Table 2: Loads and ultimate strains

\begin{tabular}{ccccccc}
\hline & \multicolumn{3}{c}{ Load [kN] } & \multicolumn{3}{c}{ Strain at ultimate [\%o] } \\
\cline { 2 - 7 } Beam & $F_{c r}$ & $F_{y}$ & $F_{u}$ & $\varepsilon_{c}$ & $\varepsilon_{s}$ & $\varepsilon_{f}$ \\
\hline A-CB & 9.38 & 30.60 & 37.22 & 3.67 & 13.38 & - \\
A-EB & 9.87 & 31.58 & 43.22 & 1.50 & 3.75 & 1.87 \\
A-IRS & 8.89 & 33.05 & 47.39 & 2.63 & 9.81 & 11.62 \\
B-CB & 9.81 & 68.12 & 76.33 & 3.68 & 17.54 & - \\
B-EB & 10.79 & 73.88 & 89.52 & 3.53 & 12.03 & 5.99 \\
B-IRS & 10.92 & 72.97 & 98.96 & 4.65 & 15.49 & 10.73 \\
\hline
\end{tabular}

Both strengthened beams A-EB and B-EB failed by sudden end debonding at SRGMconcrete interface without warnings. This 
phenomenon was probably due to the low compressive and tensile strength of the concrete, which are two parameters governing the delamination phenomenon. Instead, the beam A-IRS failed by slippage at UHTSS cords-matrix interface, after extensive cracking and the beam B-IRS failed by concrete crushing in compression. The failure modes of the RC beams strengthened with traditional EB technique were brittle (Figures 7(a), 7(c)), whereas the IRS solution provided ductile failure modes (Figures 7(b), 7(d)) due to the best adhesion of the geopolymeric matrix to the concrete substrate ensured also by the application of the matrix directly on the surface of the transverse and longitudinal reinforcing bars. In fact, with reference to the beam A-IRS (Figure 7(b)), at failure a layer of matrix remained bonded to the concrete and steel reinforcements (stirrups and longitudinal bars) and the damage was located at the UHTSS cords-matrix interface in the SRGM system.

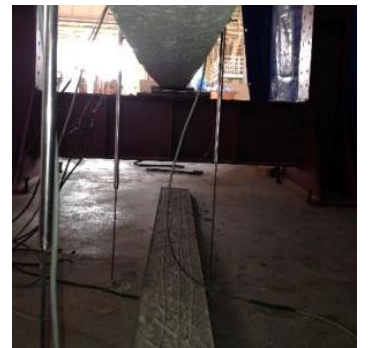

(a) A-EB

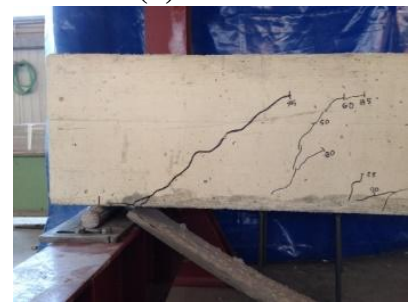

(c) B-EB

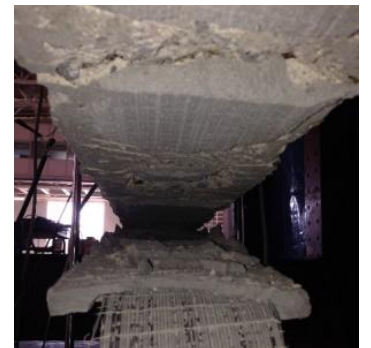

(b) A-IRS

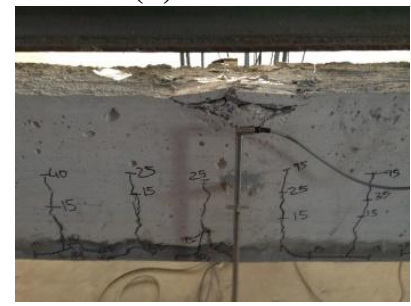

(d) B-IRS
Figure 7: Failure modes.

\subsection{Structural performance}

In order to assess the overall structural behavior of the strengthened beams, strength and ductility factors $\left(\Delta_{F}, \Delta_{\delta}\right)$ were calculated (Table 3). Specifically, $\Delta_{F}$ is the ratio between the ultimate load of the strengthened beam and that of the corresponding control beam; $\mu_{\delta}$ is the ratio between the deflection in the midspan section at failure $\left(\delta_{u}\right)$ and at yielding $\left(\delta_{y}\right)$ of the internal steel; $\Delta_{\delta}$ is the ratio of the $\mu_{\delta}$ of each strengthened beam with that of the corresponding control beam.

Table 3: Load and ductility factors

\begin{tabular}{cccc}
\hline Beam & $\mu_{\delta}$ & $\Delta_{\delta}[\%]$ & $\Delta_{F}[\%]$ \\
\hline A-CB & 8.64 & 1.00 & 1.00 \\
A-EB & 2.16 & 0.25 & 1.16 \\
A-IRS & 3.73 & 0.43 & 1.27 \\
B-CB & 4.38 & 1.00 & 1.00 \\
B-EB & 1.83 & 0.42 & 1.17 \\
B-IRS & 3.05 & 0.70 & 1.30 \\
\hline
\end{tabular}

It should be noted that the load factor $\left(\Delta_{F}\right)$ values of the strengthened beams A-EB and AIRS (group A) are about equal to values of the corresponding strengthened beams B-EB and B-IRS (group B). Specifically, the values are $1.16 \%, 1.17 \%$ and $1.27 \%, 1.30 \%$ (Table 3) for the beams strengthened with EB-SRGM and IRS-SRGM systems, respectively. This highlights that the IRS and EB strengthening techniques provided, for both groups, the same increase on load carrying capacity. Consequently, the scale effect on the ultimate load was not affected. With reference to the deflection ductility, it can be observed that the values of the $\Delta_{\delta}$ factor are higher for the beams strengthened with IRS technique than the corresponding beams strengthened with traditional EB technique. In fact, for the beams A-IRS and B-IRS the values are 0.43 and 0.70 , respectively, whereas for the beams A-EB and B-EB the ductility factors are lowest ( 0.25 and 0.42 , respectively). Furthermore, the ratio between the ductility factor of the strengthened beams A-IRS and A-EB (1.72) is about equal to that of the strengthened beams B-IRS and B-EB (1.67). This highlights that the IRSSRGM system provided, for both groups, the same increase on the ductility factor compared to the EB-SRGM system. These results show that the proposed IRS solution provided higher values of the strength and ductility factors than the traditional EB technique. 


\section{THEORETICAL PREDICTION}

\subsection{Fracture based model}

The debonding failure is essentially a crack propagation promoted by local stress intensities. This has raised interest among some researchers to take a fracture mechanics approach to the problem and develop predictive models based on elastic and fracture material properties.

In this study, the fracture mechanics based model proposed by Gunes et al. [20] for RC beams strengthened with FRP system was adopted, with adequate modifications, to predict the structural behavior of $\mathrm{RC}$ beams strengthened with innovative EB-SRGM and IRS-SRGM systems. This model defines a global failure criterion by means of an energy balance $(\triangle D=-\triangle \Pi)$ : the energy dissipated in the system during debonding $(\triangle D)$ can be determined by calculating the change in the potential energy of the system $(-\Delta \Pi)$.

The total dissipation in the system, on the load-midspan deflection curve, is depicted in Figure 8. The debonding failure criterion, after yielding of the internal tension steel, is defined by the relationship [20]:

$$
G_{F I} l_{f} b_{f}+W_{s}^{p}=\frac{P_{2 d}^{2}}{2 K_{2}}-\frac{P_{1 d}^{2}}{2 K_{1}}
$$

where $P_{2 d}$ and $P_{1 d}$ are the load values before (strengthened beam) and after (control beam) debonding, respectively, that takes place at same midspan deflection $\delta_{d} ; K_{2}$ and $K_{l}$ are the initial stiffness of the strengthened (A-EB, AIRS, B-EB, B-IRS) and control RC beams (A$\mathrm{CB}, \mathrm{B}-\mathrm{CB})$, respectively; $G_{F I I}$ is the Mode II fracture energy; $l_{f} b_{f}$ is the bond area at concrete-SRGM interface; and $W_{s}^{p}$ is the plastic energy dissipation due to reinforcement yielding. This latter, for beams tested under four-points bending, assuming that the curvature $\left(\varphi_{d}\right)$ of the cross-section essentially stays constant upon debonding, can be determined as follows:

$$
W_{s}^{p}=f_{y m} \varepsilon_{c}\left(1-c^{\prime} / c\right) A_{s} a
$$

where $\varepsilon_{c}$ is the maximum concrete strain before debonding, $c$ and $c$ ' are the neutral axis depths before and after debonding, respectively.

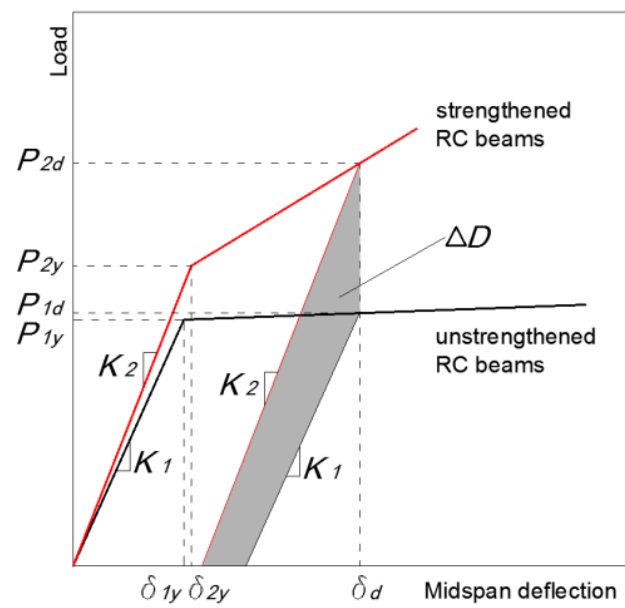

Figure 8: Energy dissipation during debonding failure.

To apply the analytical model, the theoretical load-midspan deflection curves, of the strengthened and corresponding unstrengthened RC beams must firstly be calculated. At this stage, the debonding failure mode is not computed.

The main assumptions in the analysis are: cross section is considered to remain plane after bending; perfect bond exist at SRGMconcrete and steel bars-concrete interfaces; tensile strength of concrete is neglected. The stress-strain curves assumed are: trapezoidal (with ultimate strain equal to $3.50 \%$, according to [23]) for the compression concrete, elastic-perfectly plastic for the internal steel bars and linear elastic up to failure for the SRGM system. The mean values of the mechanical properties were used in the analysis. To calculate the flexural strength of the beams, strain compatibility and force equilibrium methods were used. Theoretical load-midspan deflection curves were obtained by integration of the curvatures along the span of beams using the moment of inertia corresponding to each section. To this aim a bi-linear moment-curvature diagram was determined assuming a cracked condition; the first stage of the diagram refers to the range 0 $M_{y}$ (up to internal steel yielding) and the second stage refers to the range $M_{y}-M_{u}$ (after yielding and up to failure). Knowing the loadmidspan deflection curves of the strengthened 
beam and of the corresponding unstrengthened beam, the debonding load can be calculated by using equation 1 , expressing all quantities in function of the curvature $\left(\varphi_{d}\right)$, which is the iteration parameter.

\subsection{Energy dissipation due to debonding}

According to Gunes et al. [20] model was assumed that the debonding fracture process depends only by Mode II, because the effect of mixed-mode debonding on the performance of strengthened beams with sufficient capacity in shear, as the case of this research, can be neglected without significant error in the analysis.

The values of Mode II fracture energy should be calculate using a specific bond slip model defined for the SRGM system. However, for this inorganic based strengthening system are not yet available in literature appropriate bond-slip laws capable to predict the structural behavior of strengthened RC elements. Nevertheless, the reliability and adaptability of some bond-slip laws proposed for the FRP systems to predict the behavior of RC beams externally strengthened with Steel Reinforced Grout (SRG) and Steel Reinforced Polymer (SRP) inorganic systems were recently analyzed [24]. This study concludes that among a set of bi-linear FRP-concrete bond-slip laws, the Lu et al. [25] bond-slip model was also suitable to simulate the behavior of SRG-concrete interface.

The EB-SRGM strengthening system and failure modes of the tested beams (A-EB, BEB) were quite similar to the SRG system [10, 24]. For these reasons, the Lu et al. [25] bondslip model was adopted to evaluate the Mode II fracture energy for the beams strengthened with EB-SRGM system (A-EB, B-EB). The $G_{F I I}$ values were calculated according to the following relationships [25]:

$$
\begin{gathered}
G_{F I I}=0.308 \beta_{w}^{2} \sqrt{f_{c t m}} \\
\beta_{w}=\sqrt{\frac{2.25-b_{f} / b}{1.25+b_{f} / b}}
\end{gathered}
$$

Instead, for the $\mathrm{RC}$ beams strengthened with innovative IRS solution the equations 3 and 4 are not appropriate because no delamination at concrete-SRGM interface was observed during the experiments. In fact, for the beam A-IRS slippage at UHTSS cordsgeopolymeric matrix interface was observed, whereas for the beam B-IRS concrete crushing at midspan section was recorded. However, none bond-slip model available in literature takes into account the slippage at UHTSS cords-geopolymeric matrix interface. In order to characterize the interface behavior and define an appropriate UHTSS cordsgeopolymeric matrix interface law capable to also predict the Mode II fracture energy, single lap shear tests are carrying out at our laboratory. The details and results will be presented in future works. From the analysis of the preliminary results the $G_{F I I}$ value is 0.50 $\mathrm{N} / \mathrm{mm}$. This value was used in the analysis for the beams A-IRS and B-IRS.

\subsection{Analytical/Experimental comparisons}

The analytical and experimental comparisons in terms of load-midspan deflection curves, for the all tested beams, are shown in Figure 9.

According to the assumptions outlined in the section 4.1, the analytical curves were calculated assuming as failure mode the concrete crushing or the UHTSS rupture. The vertical and horizontal red dashed lines are the debonding deflection $\left(\delta_{d}\right)$ at the midspan section and the corresponding ultimate/debonding load $\left(P_{2 d}\right)$, respectively, evaluated by using equation 1 .

Table 4 shows the analytical results and the comparisons, in terms of ultimate load values, with the experimental data. The last column of the Table 4 gives also the absolute percentage error $\left(E_{r r}\right)$ between the experimental and theoretical values of the ultimate load. The percentage errors range from $0.08 \%$ to 4.33 $\%$. It should be noted that, for all the strengthened beams, the analytical failure mode was debonding. However, with reference to the strengthened beam B-IRS, the concrete compressive strain was equal to 3.47 $\%$, which it is very close to the analytical 
ultimate compressive strain (3.50\%). It is coherent with the experimental failure mode (concrete crushing).

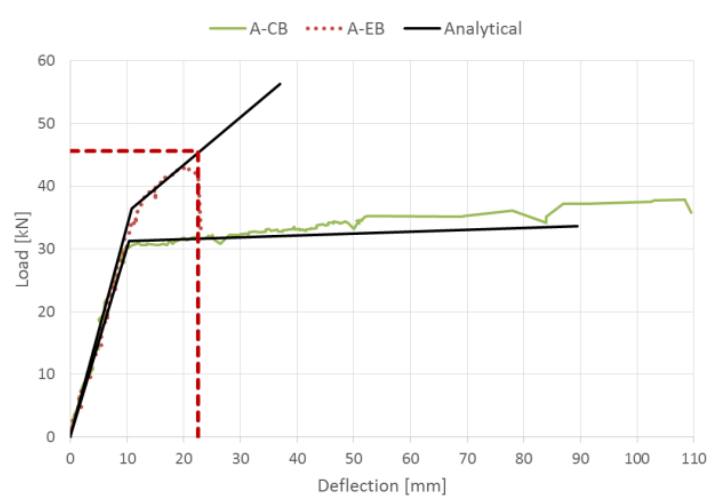

(a) A-EB

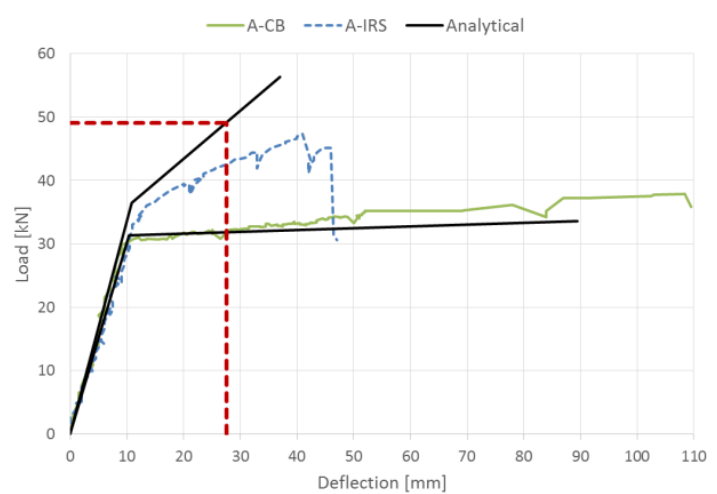

(b) A-IRS

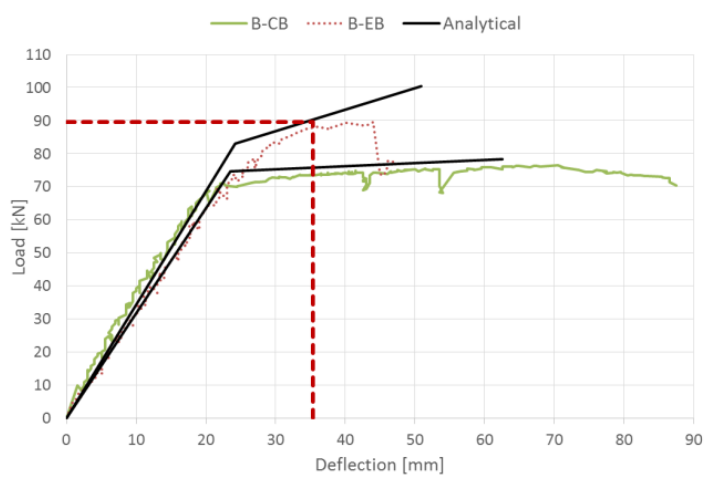

(c) B-EB

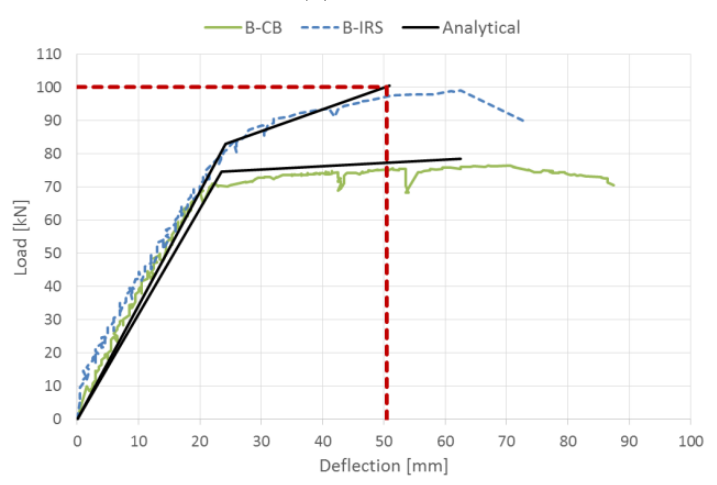

(d) B-IRS

Figure 9: Experimental/analytical comparisons.
This highlights the reliability and accuracy of the fracture based model, proposed for the FRP strengthened beams and adapted, with appropriate refinements, to predict the overall structural behavior of RC beams strengthened with EB-SRGM/IRS-SRGM systems.

\section{CONCLUSIONS}

The structural performances of an innovative eco-friendly solution for retrofitting of RC members with deteriorated cover concrete and/or corroded internal steel bars were experimentally and theoretically evaluated. Six large-scale RC beams, casted with low concrete strength and corroded smooth round/ribbed steel bars, were strengthened with a new SRGM system using traditional (EB) and innovative (IRS) techniques. A theoretical analysis using a fracture mechanics based model was carried out. The major conclusions can be summarized as follows:

- The SRGM strengthening system is an environmentally friendly composite material.

- RC beams strengthened with one layer of SRGM system had an increase of the ultimate load from $16 \%$ (EB) up to $30 \%$ (IRS), compared to the control RC beams.

- The strengthening action leads to a reduction of the structural ductility. In fact, the values of the ductility factor are lower than one for all strengthened beams. However, for the EB technique the ductility factor range from 0.25 to 0.42 , whereas for the IRS technique the ductility factor, for the same strengthened beams, range from 0.43 to 0.70 . As a result, the IRS solution provided a better ductile behavior than the traditional EB technique.

- The maximum values of the UHTSS cords strain were $11.62 \%$ and $5.99 \%$ for the IRS-SRGM and EB-SRGM systems, respectively. Therefore, the axial strain in the IRS-SRGM system was about 1.8 times that of the EB-SRGM system. Consequently, the IRS technique guarantee a higher composite action and a better overall performance than the EB solution. 
Table 4: Experimental/Analytical comparisons

\begin{tabular}{cccccccc}
\hline \multirow{2}{*}{ Beam } & \multicolumn{3}{c}{ Fracture based model } & \multicolumn{2}{c}{$F_{u}[\mathrm{kN}]$} & \multirow{2}{*}{$E_{r r}[\%]$} \\
\cline { 2 - 6 } & $G_{F I I}[\mathrm{Nmm}]$ & $\varphi_{d}[\mathrm{rad} / \mathrm{mm}]$ & $\Delta D[\mathrm{kNmm}]$ & $\varepsilon_{c}[\%]$ & Exp. & $\mathrm{An} .\left(P_{2 d}\right)$ & \\
\hline A-EB & 0.38 & $6.4310^{-5}$ & 121.34 & 2.79 & 43.22 & 45.09 & 4.33 \\
A-IRS & 0.50 & $7.8510^{-5}$ & 158.20 & 3.20 & 47.39 & 48.11 & 1.52 \\
B-EB & 0.25 & $2.6210^{-5}$ & 205.70 & 2.57 & 89.52 & 89.59 & 0.08 \\
B-IRS & 0.50 & $4.5210^{-5}$ & 427.90 & 3.47 & 98.96 & 100.04 & 1.09 \\
\hline
\end{tabular}

- No scale effect on the load carrying capacity was highlighted.

- The beams strengthened with IRS-SRGM failed by concrete crushing and/or slippage at UHTSS cords-matrix interface, whereas the beams strengthened with EB-SRGM failed by brittle end debonding (detachment of the SRGM system).

- The fracture based model, with appropriate interface parameters, showed to be an useful tool to predict the structural behavior of RC beams strengthened with EB-SRGM/IRS-SRGM systems.

Although additional theoretical and experimental investigations are needed, the results discussed in the paper highlight the effectiveness of the proposed IRS-SRGM solution, in terms of strength, ductility, failure modes, as well as shorter times, lower costs, and environmental sustainability of the strengthening intervention, compared to the traditional EB technique.

\section{REFERENCES}

[1] Badawi, M., and Soudki, K. 2010. CFRP repair of RC beams with shear-span and full-span corrosions. Journal of Composites for Construction 14(3):323335.

[2] Kreit, A., Al-Mahmoud, F., Castel, A., and François, R. 2011. Repairing corroded RC beam with Near-Surface Mounted CFRP rods. Materials and Structures 44(7):1205-1217.

[3] Xie, J., and Hu, R. 2012. Experimental study on rehabilitation of corrosiondamaged reinforced concrete beams with carbon fiber reinforced polymer. Construction and Building Materials 38:708-716.

[4] Bakis, C.E., Bank, L.C., Brown, V.L.,
Cosenza, E., Davalos, J.F., Lesko, J.J., Machida, A., Rizkalla, S.H., and Triantafillou, T.C. 2002. Fiber reinforced polymer composites for construction state-of-the-art review. Journal of Composites for Construction 6(2):73-87.

[5] ACI 440.2R-08. Guide for the Design and Construction of Externally Bonded FRP Systems for Strengthening Concrete Structures. American Concrete Institute, Farmington Hills, Michigan, USA, 2008.

[6] CNR-DT 200 R1/2013. Guide for the Design and Construction of Externally Bonded FRP Systems for Strengthening Existing Structures - Materials, RC and $P C$ structures, masonry structures. Italian National Research Council, Rome, Italy, 2013.

[7] Bruckner, A., Ortlepp, R., and Curbach, M.2006. Textile reinforced concrete for strengthening in bending and shear. Materials and Structures 39:741-748.

[8] Larbi, A.S., Agbossou, A., and Hamelin, P. 2013. Experimental and numerical investigations about textile-reinforced concrete and hybrid solutions for repairing and/or strengthening reinforced concrete beams. Composite Structures 99:152-162.

[9] Balsamo, A., Nardone, F., Iovinella, I., Ceroni, F., and Pecce, M. 2013. Flexural strengthening of concrete beams with EBFRP, SRP and SRCM: Experimental investigation. Composites Part B: Engineering 46:91-101.

[10]Bencardino, F, and Condello, A. 2014. Structural behaviour of RC beams externally strengthened in flexure with SRG and SRP systems. International Journal of Structural Engineering 5(4):346-368.

[11]Katakalos, K., and Papakonstantinou, C.G. 2009. Fatigue of Reinforced 
Concrete Beams Strengthened with SteelReinforced Inorganic Polymers. Journal of Composites for Construction 10.1061/(ASCE)10900268(2009)13:2.

[12] Menna, C., Asprone, D., Ferone, C., Colangelo, C., Balsamo, A., Prota, A., Cioffi, R., and Manfredi, G. 2013. Use of geopolymers for composite external reinforcement of RC members. Composites Part B: Engineering 45:16671676.

[13]Papakonstantinou, C.G., and Katakalos, K. 2009. Flexural behavior of reinforced concrete beams strengthened with a hybrid inorganic matrix - steel fiber retrofit system. Structural Engineering and Mechanics 31(5):1-19.

[14]Bencardino, F., and Ombres, L. 2010. Structural performance of RC beams strengthened by SRG and FRCM system. Proceedings of $34^{\text {th }}$ International Symposium on Large Structures and Infrastructures for Environmentally Constrained and Urbanised Areas; pp. 488-489.

[15]Pecce, M., Ceroni, F., Prota, A., and Manfredi, G. 2006. Response prediction of RC beams externally bonded with steelreinforced polymers. Journal of Composites for Construction 10(3):195203.

[16] Trapko, T., Urbańska, D., and Kamiński M. 2015. Shear strengthening of reinforced concrete beams with $\mathrm{PBO}$ FRCM composites. Composites Part B: Engineering 80:63-72.

[17]Kurtz, S., and Balaguru, P. 2001. Comparison of inorganic and organic matrices for strengthening of RC beams with carbon sheets. Journal of Structural Engineering 127(1):35-42.

[18] Vasconcelos, E., Fernandes, S., Barroso de Aguiar, J.L., and Pacheco-Torgal, S. 2011. Concrete retrofitting using metakaolin geopolymer mortars and CFRP. Construction and Building Materials 25:3213-3221.

[19]Davidovits, J. 2008. Geopolymer chemistry and applications, Institute Geopolymere, Morrisville.
[20] Gunes, O., Buyukozturk, O., and Karaca, E. 2009. A fracture-based model for FRP debonding in strengthened beams. Engineering Fracture mechanics 76:18971909.

[21]ST2-0910. Range of stainless steel reinforcing fabrics for structural consolidation, Kimisteel INOX. Kimia S.p.A., 2015.

[22]ST1-0613. R4 Normal curing thixotropic geopolymeric mortar for rehabilitation in compliance with the marking requirements laid down by UNI EN 15043 for R4 mortars and the requirements for armor protection systems defined in EN 1504-7, Betonfix MONOLITE N. Kimia S.p.A., 2015.

[23]Eurocode 2. European Committee for Standardization, Design of Concrete Structures - Part 1-1: General Rules and Rules for Buildings, EN 1992-1-1: 2004.

[24]Bencardino, F., and Condello A. 2015. SRG/SRP-concrete bond-slip laws for externally strengthened RC beams. Composite Structures 132:804-815.

[25]Lu, X.Z., Teng, J.G., Yea, L.P., and Jiang, J.J. 2005. Bond-slip models for FRP sheets/plates bonded to concrete. Engineering Structures 27:920-937. 